\title{
Determination of subsidence of base with intensive soaking of subsidence soil
}

\author{
Viktor Yarkin ${ }^{1 *}$ and Nataliia Lobacheva ${ }^{2}$ \\ ${ }^{1}$ Donbas National Academy of Civil Engineering and Architecture, 2, Derzhavina Str., Makeyevka, \\ DPR, 286123 \\ ${ }^{2}$ Moscow State University of Civil Engineering, Yaroslavskoe shosse, 26, Moscow, 129337, Russia
}

\begin{abstract}
The article considers study of influence of coefficient $\mathrm{k}_{\mathrm{sl}}$ on subsidence value. In course of study, it was revealed that coefficient $k_{s l}$, determined according to normative documents of Russian Federation, has a limited scope and does not always lead to sufficiently satisfactory and theoretically justified results. In this article, a range of pressures on the bases up to $500 \mathrm{kPa}$ has been investigated. This range makes it possible to take into account the redistribution of pressures in case of uneven deformations of the base of the foundations. These pressures in some areas can significantly exceed calculated resistance of subsidence soil. When pressure increases more than $500-600 \mathrm{kPa}$, subsidence decreases due to additional compaction of subsidence soil without soaking due to destruction of structural bonds from pressure value. Therefore, at high pressures on the base, proportion of subsidence deformations in the total vertical deformation decreases and the proportion of deformations caused by the development of shear zones increases. Dependence of thickness of lower subsidence zone on pressure by at different widths of bottom of a foundation are presented. Proposed algorithm for determining subsidence deformation by external load on base, allows to separate subsidence deformation from shear deformation of soil and thus obtain more accurate values of subsidence deformations in entire range of possible pressures on foundation Dependences of subsidence on pressure determined by normative documents and proposed algorithm for different foundation widths are given. A comparative analysis of values of subsidence at different foundation widths is given.
\end{abstract}

\section{Introduction}

Territories with subsident soils are widely distributed around the world and are found on almost all continents. The construction of buildings and structures on subsident soils, as a rule, requires additional protection measures against uneven deformations of base caused by the special properties of subsident soils, the thickness of which can reach up to $30 \mathrm{~m} \mathrm{[1}$, $2,3]$. Researchers have been dealing with the problem of building on subsident soils since the late 30 s of last century, but this problem does not lose its relevance at present time [4-

*Corresponding author: yarkinvv@mail.ru 
9]. Reliable determination of values of subsidence from external load and from own weight of soil is very important, because it depends on it choice of effective measures to protect buildings and structures from uneven deformations of base caused by subsidence of soil.

In accordance with current normative documents $[1,2]$ it is recommended to determine subsidence by method of layer-by-layer summation using model of a linearly deformable elastic half-space. When determining subsidence by this method, is used correction coefficient $k_{s l}$, which has a defined area of correctly application and in some cases can lead to calculation results that differ significantly from real values.

\section{Methods}

\subsection{Determination of subsident in accordance with normative documents of Russian Federation}

Formula for determining subsidence when soaking large areas from above or soaking from below when underground water level rises according to normative documents of Russian Federation $[1,2]$ :

$$
s_{s l, p(q)}=\sum_{i=1}^{n} \varepsilon_{s l, i} h_{i} k_{s l, i}
$$

where $\varepsilon_{s l, i}$ - relative subsidence of $i$-th layer of soil, at a pressure equal to total vertical stress in $i$-th layer $\sigma_{z, i} ; h_{i}$ - thickness of $i$-th soil layer; $n$ - number of layers into which the subsidence zones are separated upper subsidence zone $h_{s l, p}$ and (or) lower subsidence zone $h_{s l, g} ; k_{s l, i}-$ coefficient taking into account the working conditions of bases foundations.

When summing in the upper subsidence zone $h_{s l, p}$ coefficient $k_{s l, i}$, in accordance with [1, 2], will be equal to:

- when width of bottom of a foundation $b \geq 12 \mathrm{M}-1.0$;

- when width of bottom of a foundation $\mathrm{b} \leq 3 \mathrm{M}-$ by formula:

$$
k_{s l, i}=0.5+1.5\left(p-p_{s l, i}\right) / p_{0}
$$

where $p$ - average pressure under bottom of a foundation; $p_{s l, i}$ - initial subsidence pressure $i$ - th layer of soil; $p_{0}$ - pressure equal to $100 \mathrm{kPa}$;

- when width of bottom of a foundation $3 \mathrm{~m}<b<12 \mathrm{~m}$ - by interpolating between values $k_{s l, i}$, obtained by $b=3 \mathrm{~m}$ and $b=12 \mathrm{~m}$.

When summation in lower subsidence zone $h_{s l, g}$ accept $k_{s l}=1$ by $H_{s l} \leq 15 \mathrm{~m}$ and $k_{s l}=1.25$ by $H_{s l} \geq 20 \mathrm{~m}$. For intermediate values of subsidence thickness $H_{s l}$, the correction coefficient is determined by interpolation between above values.

It should be noted that coefficient $k_{s l}$, determined for lower subsidence zone varies in range from 1 to 1.25 , while for upper zone it depends linearly on amount of pressure on the base. Therefore, value of coefficient $k_{s l}$, when determining it for the upper and lower subsidence zones can lead to a difference of several times. This should be taken into account, because when determining total subsidence, accuracy of dividing subsidence thickness into upper and lower zones can significantly affect by results.

According to normative documents $[1,2]$, breakdown of subsidence thickness into upper and lower zones is performed in this way.

The lower bound of upper zone $h_{s l, p}$ corresponds to depth, where the total vertical stresses are equal to the initial subsidence pressure $\sigma_{z}=\sigma_{z p}+\sigma_{z g}=P_{s l}$ or depth, where $\sigma_{z}$ is minimal, if $\sigma_{z, \min }>P_{s l}$. The lower subsidence zone $h_{s l, g}$ is defined starting from depth where $\sigma_{z}=P_{s l}$ or $\sigma_{z}$ is minimal, if $\sigma_{z, \min }>P_{s l}$, and to lower boundary of subsidence thickness. It is also possible for a neutral zone to appear in the soil massif, within which the total vertical 
stresses are less than the initial subsidence pressure $\sigma_{z}=\sigma_{z p}+\sigma_{z g}<P_{s l}$. It divides the subsidence thickness into the upper and lower subsidence zones, respectively.

There are also other proposals for dividing the subsidence thickness into upper and lower subsidence zones, for example, [10].

\subsection{Aspects of determining the coefficient $\mathbf{k}_{\mathrm{sI}}$}

In accordance with [11] coefficient of working conditions of base $k_{s l}$ taken constant for depth $1.5 \cdot \mathrm{b}$ equal to 2 , and for rest of subsidence thickness -1.5 . Further amendments were made to [11] and coefficient of working conditions of base $k_{s l}$ taken constant for depth $1.5 \cdot \mathrm{b}$ by $b=0.5-2.0 \mathrm{~m}$ equal to 2 , by $\mathrm{b}>2.0 \mathrm{~m}$ equal to 1 , and for rest of subsidence thickness 1.0 .

However, calculation of subsidence's using these coefficient values resulted in results that were significantly different from those actually measured. At the same time, according to observations of many authors, coefficient values in upper zone of subsidence for foundations of a small area were more than 2, and in lower zone, on contrary, the $k_{s l}$ could reach a value of 1.5 only with large thicknesses of strongly subsiding soils [12].

In this regard, later, according to the results of statistical processing of a series of tests of subsidence soils, performed with stamps by area from 0.5 to $4 \mathrm{~m}^{2}$ was proposed two empirical formula for determining the coefficient of soil working conditions in upper zone of subsidence strata [13]: depending on pressure on the bottom of a foundation and initial subsidence pressure (2) and depending from value of estimated subsidence of foundation from external load $s_{s l, p}^{\prime}$, defined by (1) with $k_{s l}=1$.

$$
k_{s l}=1+0.2 \cdot s_{s l, p}^{\prime} / s_{0}
$$

where $s_{s l, p}$ - estimated subsidence of foundation from external load at $k_{s l}=1 ; s_{0}-$ settlement taken equal to $1 \mathrm{~cm}$.

The correlation coefficient for both formulas is almost the same, however, regulatory documents recommend using formula (2), since it takes into account a larger number of factors [13].

According to normative documents, design scheme for determining coefficient $k_{s l}$ provides for one-dimensional compaction of soil, but both volumetric and shear deformations occur during subsidence. And their values can reach up to $70 \%$ of subsidence value [14]. This indicates imperfection of design scheme itself according to normative documents of Russian Federation. Therefore, there are currently a large number of recommendations for improving coefficient $k_{s l}$, which suggest introducing several additional parameters.

\subsection{Research of influence of coefficient $\boldsymbol{k}_{s /}$ on subsidence value}

Let us consider two variants of engineering-geological conditions represented by a tenmeter thickness of subsident soils, which, according to classification proposed by M. N. Gol'dshtejn [15], are:

a) low subsidence soil (by $p=200 \mathrm{kPa} \quad 0,01<\varepsilon_{s l} \leq 0.03$ );

b) medium subsidence soil (by $p=200 \mathrm{kPa} \quad 0.03<\varepsilon_{s l} \leq 0.07$ ).

At the same time, subsidence from self weight soil in considered low-subsidence soils is $4.5 \mathrm{~cm}$, and in the medium-subsidence soils is $20.5 \mathrm{~cm}$. In accordance with classification [2] considered engineering - geological conditions refer to territories by subsidence: a-type I; b-type II.

According to works $[15,16]$, when pressure increases more than $500-600 \mathrm{kPa}$, subsidence decreases due to additional compaction of subsidence soil without soaking due 
to destruction of structural bonds from pressure value. Therefore, at high pressures on the base, proportion of subsidence deformations in the total vertical deformation decreases and the proportion of deformations caused by the development of shear zones increases. In this regard, in this paper, pressure range increases to $500 \mathrm{kPa}$, although usually in construction practice, pressure range on base of foundation is considered to be up to $300 \mathrm{kPa}$. Increasing pressure range allows you to take into account redistributing pressures on the bottom of a foundation, which arise due to uneven deformations of base. These pressures in some areas can significantly exceed calculated resistance of subsidence soil.

Figure 1 shows dependence of thickness of lower subsidence zone on pressure at different widths on the bottom of a foundation with ratio of sides $l / b=1$. In this and Figure 2, dependencies obtained by [1].
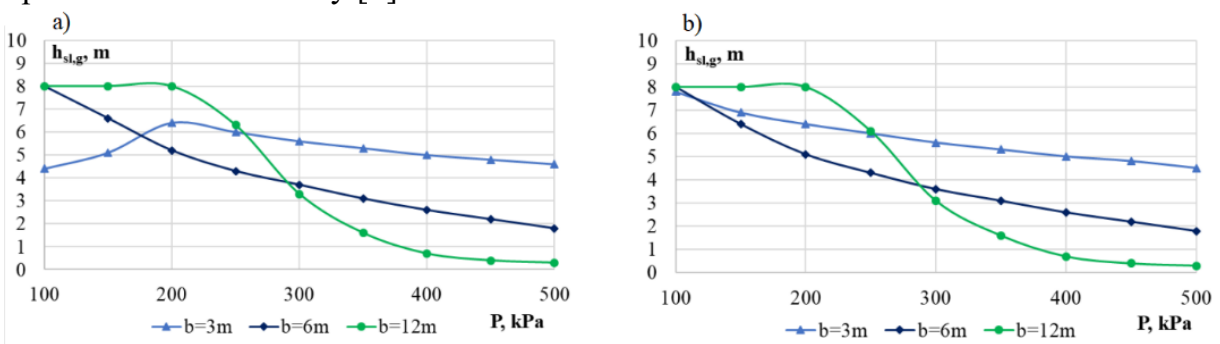

Fig. 1. Dependence of thickness of lower subsidence zone on pressure: a-type I; b-type II

At constant pressure on the base, an increase in width of a foundation leads to an increase the depth at which $\sigma_{z}$ is minimal [17]. This is reason for a decrease in lower subsidence zone $h_{s l, g}$ and an increase in upper subsidence zone $h_{s l, p}$ according to [1]. However, the use of a higher correction coefficient for upper subsidence zone under certain conditions will lead to an increase in the subsidence, but this is not consistent with results of field observations [18].
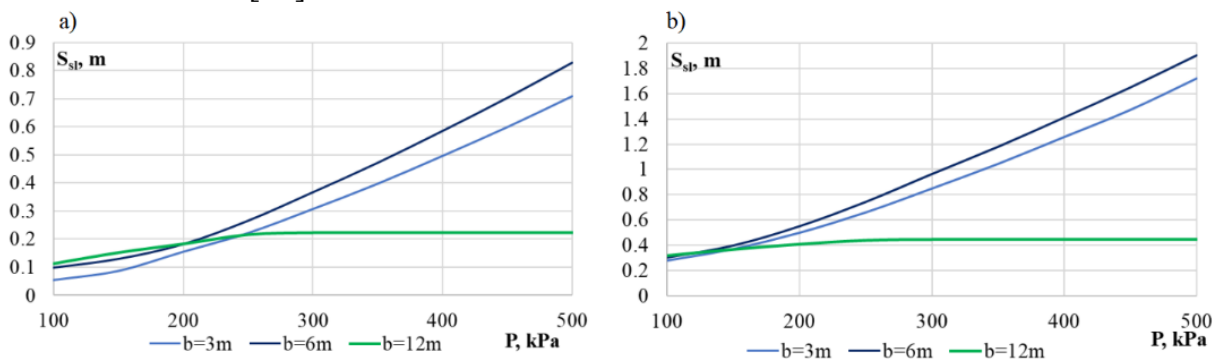

Fig. 2. Pressure subsidence dependences: a-type I; b-type II

As can be seen from Figure 2, if foundation width equal to or greater than $12 \mathrm{~m}$ and pressure value is more than $300 \mathrm{kPa}$, the subsidence value will be constant, since in this case there are practically no shear deformations. Accordingly, value of coefficient $k_{s l}$ is assumed to be 1 .

The subsidence determined by [1,2] at pressures above $300 \mathrm{kPa}$ and with width bottom of a foundation of less than $6 \mathrm{~m}$ can be several times greater than subsidence for foundations with a width of $12 \mathrm{~m}$. This is because coefficient $k_{s l}$ depends linearly on pressure value. But according to observations [16], subsidence of soil should be reduced as a result of its compaction without soaking under action of high pressures on base. That is, obtained values contradict data of field observations. The obtained values of subsidence are greatly overestimated, since according to observations of various authors $[16,17]$, the maximum relative subsidence for medium-and high-subsidence soils usually corresponds to a pressure of no more than $300 \mathrm{kPa}$. 
From this we can conclude that coefficient $k_{s l}$, determined by formula (2) has a limited field of application and does not always lead to sufficiently satisfactory results [19].

It is generally assumed that coefficient $k_{s l}$ takes into account horizontal (lateral) seals $[13,14]$. Since zones of lateral displacements of compacted from external load of subsidence soil located at perimeter of foundation, increasing size of bottom of a foundation leads to a decrease in relationship of perimeter to the area of bottom of a foundation, respectively, to reduce the influence of a lateral displacements of the soil on magnitude of vertical subsidence. Accordingly, when width of bottom of a foundation is 12 $\mathrm{m}$ or more, lateral movements are neglected, taking $k_{s l}=1$. Given peculiarity of formation of shear deformation zones, according to authors, it follows that to limit upper subsidence zone, to which correction coefficient is applied, to a depth where $\sigma_{z}$ is minimal, if $\sigma_{z, \min }>$ $P_{s l}$, but no more than estimated depth of development of shear zones [20].

\subsection{The algorithm for determining subsidence deformations proposed by authors}

1. The subsidence thickness along considered vertical line is divided into elementary layers with a thickness of 0.1-2 m, depending on accuracy of initial data and required accuracy of results, taking into account engineering-geological structure, flooding and stress state of soil massive.

2. For each elementary layer, a check is performed - whether this elementary layer of subsidence soil falls along considered vertical into watered zone. If it does not fall, then subsidence deformations of this elementary layer will be zero.

3. In each watered elementary layer of subsidence soil, stresses $\sigma_{z g, i}\left(\sigma_{z g, s a t, i}\right), \sigma_{z, i}$ and are determined and if they exceed initial subsidence pressure $p_{s l, i}$ in this layer, the corresponding subsidence deformations are determined by formulas:

$$
\begin{aligned}
& s_{s l, g, i}=\varepsilon_{s l, g, i} \cdot h_{i} \\
& s_{s l, i}=\varepsilon_{s l, i} \cdot h_{i} \\
& s_{s l, p, i}=s_{s l, i}-s_{s l, g, i}
\end{aligned}
$$

4. Since coefficient takes into account horizontal (lateral) compaction of subsidence soil under shear deformations $[14,18,19]$, then as the upper zone of subsidence, within which this coefficient will be taken into account, we take the zone in which shear deformations have a significant influence on the total value of subsidence. The upper zone of subsidence $h_{s l, p}$ is measured starting from the bottom of a foundation and up to lower border of upper zone, which corresponds to depth, where $\sigma_{z}=p_{s l}$ or depth, where $\sigma_{z}$ is minimal, if $\sigma_{z, \text { min }}>$ $p_{s l}$, but is assumed to be no more than $0.25 \cdot b$ and no more than value determined by formula:

$$
h_{s l, p} \leq b \cdot \frac{12-b}{10} \cdot \frac{\left(p-p_{s l}\right)}{p_{0}}
$$

where $b$ - width of bottom of a foundation, when $b>12 \mathrm{~m}$ accepted as equal $12 \mathrm{~m} ; p-$ average pressure on the bottom of a foundation; $p_{s l}$ - initial subsidence pressure at the level of bottom of a foundation; $p_{0}$ - pressure equal to $100 \mathrm{kPa}$.

5. If size of subsidence thickness exceeds upper subsidence zone, the subsidence from external load can be observed beyond limits upper subsidence zone, including in lower subsidence zone, but shear deformations will occur only in the upper subsidence zone, in which stresses from external load significantly exceed the stresses from their self weight. In this regard, select subsidence deformations from external load that occur only in upper zone of subsidence $s_{s l, p}$ 


$$
s_{s l, p}^{\prime}=\sum_{i=1}^{m} s_{s l, p, i}
$$

where $m$ - number of elementary layers within upper subsidence zone.

6. Slightly modifying the formula (3), define

$$
k_{s l}=0.2 \cdot s_{s l, p}^{\prime} / s_{0}
$$

where $s_{s l, p}^{\prime}$ - subsidence of foundation from external load by $k_{s l}=1$ within the upper subsidence zone only; $s_{0}-$ settlement taken equal to $1 \mathrm{~cm}$.

7. The calculated values of subsidence from external load and from self weight of soil are determined by following formulas:

$$
\begin{aligned}
& s_{s l, p}=\sum_{i=1}^{n} s_{s l, p, i}+s_{s l, p}^{\prime} \cdot k_{s l} \\
& s_{s l, g}=k_{s l, g} \cdot \sum_{i=1}^{n} s_{s l, g, i}
\end{aligned}
$$

where $k_{s l, g}$ - coefficient determined for lower subsidence zone, as in formula (1)

8 . The estimated value of subsidence:

$$
s_{s l}=s_{s l, p}+s_{s l, g}
$$

\section{Results and Discussion}

In accordance with proposed algorithm and current normative documents [1, 2], dependences of subsidence on pressure were constructed for different widths of bottom of a foundation (figure 3,4).

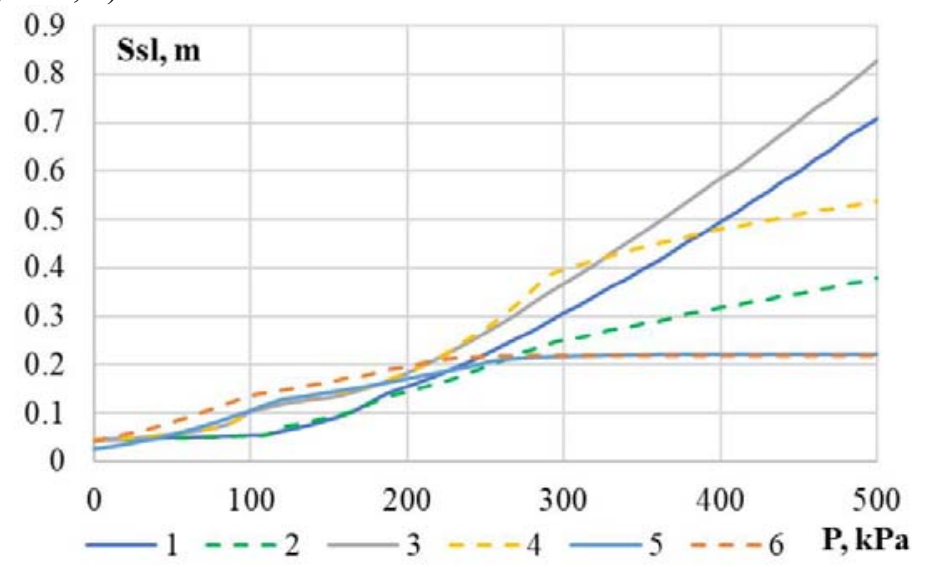

Fig. 3. Dependence of subsidence on pressure at foundation width from 3 to $12 \mathrm{~m}$ (the values obtained from [1] are shown in solid lines, and according to proposed algorithm are shown in dotted lines): $1,2-$ by $b=3 \mathrm{~m} ; 3,4-$ by $b=6 \mathrm{~m} ; 5,6-$ by $b=12 \mathrm{~m}$. 


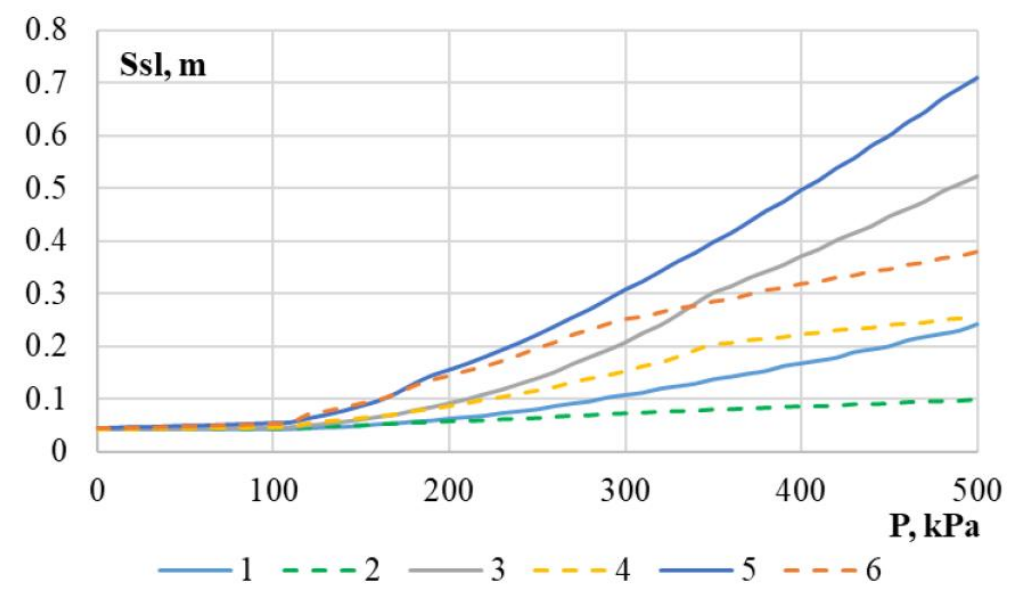

Fig. 4. Dependence of subsidence on pressure at foundation width from 1 to $3 \mathrm{~m}$ (the values obtained from [1] are shown in solid lines, and according to proposed algorithm are shown in dotted lines):1, 2 - by $b=1 \mathrm{~m} ; 3,4$ - by $b=2 \mathrm{~m} ; 5,6-$ by $b=3 \mathrm{~m}$.

Table 1. Comparative analysis of value of subsidence with a foundation width of $3 \mathrm{~m}$.

\begin{tabular}{|c|c|c|c|}
\hline $\begin{array}{c}\text { Pressure } \boldsymbol{P} \\
(\mathbf{k P a})\end{array}$ & $\begin{array}{c}\boldsymbol{S}_{\mathbf{s} \boldsymbol{l}}(\mathbf{m}) \\
\text { (according to } \\
\text { normative } \\
\text { documents) }\end{array}$ & $\begin{array}{c}\boldsymbol{S}_{\mathbf{s} \boldsymbol{}}(\mathbf{m}) \\
\text { (according to } \\
\text { proposed } \\
\text { algorithm) }\end{array}$ & Difference (\%) \\
\hline 0 & 0.0439 & 0.0452 & 2.88 \\
\hline 50 & 0.0487 & 0.0488 & 0.20 \\
\hline 100 & 0.0537 & 0.054 & 0.56 \\
\hline 150 & 0.0862 & 0.0921 & 6.41 \\
\hline 200 & 0.1545 & 0.1445 & -6.92 \\
\hline 250 & 0.2211 & 0.1968 & -12.35 \\
\hline 300 & 0.3069 & 0.2523 & -21.64 \\
\hline 350 & 0.397 & 0.2857 & -38.96 \\
\hline 400 & 0.4962 & 0.3193 & -55.40 \\
\hline 450 & 0.5991 & 0.3467 & -72.80 \\
\hline 500 & 0.7091 & 0.3803 & -86.46 \\
\hline
\end{tabular}

Table 2. Comparative analysis of value of subsidence with a foundation width of $6 \mathrm{~m}$.

\begin{tabular}{|c|c|c|c|}
\hline $\begin{array}{c}\text { Pressure } \boldsymbol{P} \\
\text { (kPa) }\end{array}$ & $\begin{array}{c}\boldsymbol{S}_{\boldsymbol{s l}}(\mathbf{m}) \\
\text { (according to } \\
\text { normative } \\
\text { documents) }\end{array}$ & $\begin{array}{c}\boldsymbol{S}_{\mathbf{s l}} \text { (m) } \\
\text { (according to } \\
\text { proposed } \\
\text { algorithm) }\end{array}$ & Difference (\%) \\
\hline 0 & 0.0412 & 0.0432 & 4.63 \\
\hline 50 & 0.0563 & 0.0565 & 0.35 \\
\hline 100 & 0.1022 & 0.103 & 0.78 \\
\hline 150 & 0.1309 & 0.14 & 6.50 \\
\hline 200 & 0.1825 & 0.1821 & -0.22 \\
\hline 250 & 0.2657 & 0.2729 & 2.64 \\
\hline 300 & 0.3669 & 0.396 & 7.35 \\
\hline 350 & 0.4716 & 0.4415 & -6.82 \\
\hline 400 & 0.585 & 0.4798 & -21.93 \\
\hline 450 & 0.7028 & 0.5095 & -37.94 \\
\hline 500 & 0.8277 & 0.5361 & -54.39 \\
\hline
\end{tabular}


When conducting a comparative analysis value for foundations with a width of $12 \mathrm{~m}$, the results of subsidence values calculated according to current normative documents and according to proposed algorithm are almost the same.

\section{Conclusions}

1. Coefficient $k_{s l}$, determined by formula (2) in accordance with [1], has a limited correct scope (approximately from $P_{s l}$ to $300 \mathrm{kPa}$ ) and does not always lead to sufficiently satisfactory and theoretically justified results. At pressures of more than $300 \mathrm{kPa}$, subsidence deformations from external load can be overestimated by $100 \%$ or more. This is explained to linear dependence of coefficient $k_{s l}$ on pressure, which contradicts results of field observations [16], since under action of high pressures on subsidence soil, its compaction occurs without soaking and, accordingly, its subsidence decreases.

2 . Within correct scope of application of coefficient $k_{s l}$, determined by formula (2) in accordance with [1], the difference in results of determining subsidence according to [1] and proposed algorithm is no more than 7\%. With foundation widths less than $6 \mathrm{~m}$ and foundation pressures of more than $300 \mathrm{kPa}$, the discrepancy in the results can reach $100 \%$ or more.

3. The proposed formula for determining coefficient $k_{s l}$ is based on empirical dependence (3) and has a correlation coefficient almost the same as the formula (2), but at the same time, it allows you to take into account the decrease in relative subsidence when the pressure rises above a certain level.

4. Proposed algorithm to calculate subsidence deformation from load on the base, allows to separate subsidence deformation from shear deformation of the soil and thus obtain more accurate values of subsidence deformations in the entire range of possible pressures on foundation.

\section{References}

1. Set of RF Rules SP 21.13330.2012 Zdanija i sooruzhenija na podrabatyvaemyh territorijah i prosadochnyh gruntah. (Minregion Rossii, Moscow, 2012)

2. Set of RF Rules SP 22.13330.2016 Soil Bases of Buildings and Structures. (Standartinform, Moscow, 2016)

3. A. S. Cherny`sh, Speczificheskie svojstva prosadochny`kh gruntov (Belgorodskij gosudarstvenny`j tekhnologicheskij universitet im. V.G. Shukhova, Belgorod, 2015)

4. V. I. Krutov, A. S. Kovalev, V. A. Kovalev, Proektirovanie i ustrojstvo osnovanij i fundamentov na prosadochny`kh gruntakh (ASV, Moscow, 2013)

5. A. C. Waltham, Ground subsidence (Blackie, United Kingdom, 1989)

6. J. Sundell, E Haaf, T. Norberg, C. Alén, M. Karlsson, Risk Analysis, 39-1, p. 105-124 (2019)

7. Metodicheskoe posobie po proektirovaniju osnovanij i fundamentov na prosadochnyh gruntah (Ministerstvo stroitel'stva i zhilishhno-kommunal'nogo hozjajstva Rossijskoj Federacii, Moscow, 2020)

8. Bijuan Huang, Shu Longcang, Y. S. Yang, Water resources management, 26.14 p. 4225-4239 (2012)

9. A. Prokopov, M. Prokopova, Y. Rubtsova MATEC Web of Conferences, 106 p. 1-9 (2017) 
10. DSTU-N B V.1.1-44:2016 Nastanova shhodo proektuvannja budivel' i sporud na prosidajuchih truntah (DP "UkrNDNC", Kiev, 2016)

11. SNiP II-B.2-62 Osnovanija $i$ fundamenty zdanij $i$ sooruzhenij na prosadochnyh gruntah (Gosudarstvennoe izdatel'stvo literatury po stroitel'stvu, arhitekture i stroitel'nym materialam, Moscow, 1962)

12. A. A. Grigorjan, Osnovanija, fundamenty i mehanika gruntov, 2 p. 17-21 (2001)

13. V. I. Krutov, Raschet fundamentov na prosadochnyh gruntah (Strojizdat, Moscow, 1972)

14. Z. G. Ter-Martirosyan, Mehanika gruntov (ASV, Moscow, 2005)

15. M. N. Gol'dshtejn, N. M. Makarenko, Osnovanija, fundamenty i mehanika gruntov, 6 p. 10-13 (1970)

16. Ja. D. Gil'man, V. P. Anan'ev, Stroitel'nye svojstva lessovyh gruntov i proektirovanie osnovanij i fundamentov (RISI, Rostov na Donu, 1971)

17. Ju. M. Abelev, M. Ju. Abelev, Osnovy proektirovanija i stroitel'stva na prosadochnyh makroporistyh gruntah (Strojizdat, Moscow, 1968)

18. Ja. D. Gil'man, Osnovanija i fundamenty na lessovyh prosadochnyh gruntah (SevkavNIPIagroprom, Rostov na Donu, 1991)

19. A. A. Mustafaev, Fundamenty na prosadochnyh i nabuhajushhih gruntah (Vysshaja shkola, Moscow, 1989)

20. V. V. Yarkin, H. V. Kukhar, Modern industrial and civil construction, 13 (2) p. 111 119 (2017) 